\title{
RELAÇÕES DE GÊNERO: CONFLITOS VISIBILIZADOS NAS PAREDES DA UNIVERSIDADE
}

\author{
GENDER RELATIONS: CONFLICTS MADE VISBBLE ON THE WALLS OF THE UNIVERSITY
}

\section{RESUMO}

Neste artigo, problematizamos as questões de gênero entre estudantes universitários/ as a partir da análise de intervenções gráficas por eles/as realizadas nas dependências de uma instituição de ensino superior do Brasil. As imagens fotográficas dessas intervenções foram analisadas através da perspectiva dialógica de Bakhtin, sendo foco das discussões as tensões e violências que visibilizam características das relações de gênero naquele contexto. A pesquisa possibilita compreender o modo como o espaço físico se converte, com as intervenções das/dos estudantes e as respostas das autoridades institucionais, em um espaço dialógico de expressão dos acordos, disputas, (des)afetos que compõem a arena de vozes sociais da universidade pública. Assim, ao passo que o espaço é constituidor de subjetividades, configura-se também como um importante lócus para investigações que se dedicam às complexas relações entre sujeito e sociedade, e entre sujeitos constituídos em diferenças interseccionadas de gênero, classe, raça, etnia e outras.

Palavras-chave: Gênero. Estudantes universitários. Dialogismo. Intervenções gráficas. Universidade pública. Política.

\begin{abstract}
In this article we analyze the conflicts involving gender issues among university students triggered by graphic interventions performed on the premises of a higher education institution. Photographic images of these interventions were analyzed from Bakhtin's dialogical perspective, which focused on the tensions and violence that highlight characteristics of gender relations in that context. The study made it possible to understand how the physical space is converted, with the interventions of the students and the responses of the institutional authorities, into a dialogical space for the expression of the agreements, disputes and affections that build the arena of social voices of the public university. Being, at the same time, a space that constitutes subjectivities, it is configured as an important locus for investigations that focus on the complex relationships between subject and society and between subjects constituted in intersecting differences of gender, class, race, ethnicity and many others.
\end{abstract}

Graziele Aline Zonta

Universidade Federal do Paraná (UFPR) - Brasil. gzonta@hotmail.com

Andréa Vieira Zanella

Universidade Federal de Santa Catarina (UFSC) - Brasil. avzanella@gmail.com

Mara Coelho de Souza Lago

Universidade Federal de Santa Catarina (UFSC) - Brasil. maralago7@gmail.com 
Keywords: Gender. University students. Dialogism. Graphic interventions. Public university. Politics.

\section{Introdução}

Neste artigo, analisamos os conflitos que envolvem as questões de gênero entre estudantes de uma instituição de ensino superior. Os referidos conflitos foram desencadeados a partir de intervenções gráficas realizadas por estudantes nas paredes do Departamento de Arquitetura e Urbanismo (DAU), da Universidade Federal do Paraná (UFPR), e registrados pela primeira autora por meio de fotografias. As intervenções gráficas, registradas nessas imagens, consistiram no material analisado, sendo o foco das discussões as tensões e violências que visibilizam características das relações de gênero no contexto já mencionado.

Partimos da perspectiva dialógica de Bakhtin (2003; 2012) para afirmar as intervenções como um modo de linguagem que medeia as relações sociais e participa da constituição das subjetividades que compartilham o contexto social em foco. Nessa abordagem, concebemos que a relação de alteridade possibilita a apropriação das vozes sociais que fundamentam e expressam a consciência dialógica, sendo o enunciado, por sua vez, o modo concreto de realização da linguagem, de objetivação da consciência nos tensos campos discursivos, na arena de vozes sociais em debate (BAKHTIN, 2003). Enunciados compõem os elos da cadeia histórica que comunica os sujeitos, os tempos e espaços, e é por meio deles que cada participante do campo, desde sua posição única e insubstituível no mundo, manifesta sua avaliação sobre a realidade.

Desse modo, assumimos as intervenções nas paredes da universidade como enunciados concretos ali objetivados, os quais visibilizam variadas vozes sociais em suas diferenças. Diferenças que, muitas vezes, se atualizam em tensões e eclodem em conflitos declarados, como o relatado aqui através das imagens analisadas. Esses enunciados nos exigiram falar de gênero, relação que, conforme Joan Scott (1990), é o primeiro locus de manifestação e vivência das assimetrias de poder na sociedade, onde germinam os conflitos que, não raro, se manifestam em violências de variados graus.

\section{Método}

As intervenções gráficas, foco do presente estudo, constituíram uma cadeia de enunciados responsivos a eventos ocorridos no DAU da UFPR, no ano de 2015, os quais serão relatados no decorrer da escrita. Foi a repercussão desses eventos no cotidiano universitário que motivou o registro fotográfico das intervenções produzidas pelos/as estudantes nas paredes do DAU. 
As fotografias foram produzidas uma vez por semana, no período de dois meses, entre julho e agosto de 2015. Foi utilizada a câmara digital acoplada ao telefone celular para os registros. Ao todo, foram produzidas 30 imagens. Além das fotos produzidas pela pesquisadora, foram também utilizados, para fins de análise, imagens e textos divulgados em diferentes mídias, como jornais locais e páginas online da universidade.

Consoante às afirmações de Zonta e Zanella (2019), compreendemos as intervenções produzidas pelos/as estudantes nos espaços da universidade como enunciados concretos dos sujeitos que compartilham uma arena de embates, de acordos, de negações, de adesões parciais, que fazem visibilizar os posicionamentos ético-estéticos de seus autores. Ao fazermos uso de imagens fotográficas nas análises, concebemos esse recurso como produção discursiva que, ao mesmo tempo, expressa e provoca as tensões sociais que compõem o campo dialógico em que se realizam (TITTONI \& ZANELLA, 2016).

Para aprofundar o estudo e analisar as intervenções gráficas dos/as estudantes, foram acessados documentos institucionais produzidos por instâncias diretivas da UFPR, e textos jornalísticos que reportavam os eventos associados às intervenções em foco. O diálogo entre as imagens e textos produzidos foi realizado com base na perspectiva da análise do discurso bakhtiniana (Bakhtin, 2003; 2012), a qual possibilitou identificar as vozes sociais que se fazem ouvir por meio das imagens e escritos, deixando emergirem os embates discursivos que se realizam entre os/as participantes desse espaço universitário.

O que irrompeu no espaço, com a violência evidenciada nas imagens e palavras retratadas pela câmara da pesquisadora, foram as tensões e conflitos nas relações entre alguns alunos e alunas do curso de Arquitetura e Urbanismo da UFPR, atualizando profundas disputas e disparidades constituintes das relações de gênero e expressões de sexualidades entre os sujeitos envolvidos na situação, extrapolando o campus universitário e chegando aos veículos de comunicação em massa da cidade.

\section{Sobre gênero e violência: alguns apontamentos}

Nas ciências humanas é sabido que teorias e pesquisas sucedem os movimentos sociais que reivindicam direitos de grupos específicos das populações, inaugurando, muitas vezes, novas áreas de conhecimento. Foi o que aconteceu com os estudos da mulher, de mulheres e posteriormente, de gênero, ligados à chamada segunda onda ${ }^{1}$ de movimentos feministas que se formou nos países do Norte Global, e que nos Estados Unidos teve o protagonismo de mulheres negras, no questionamento do sujeito do feminismo como uma mulher universal. O modelo, evocado na ideia de mulher como uma categoria universal, fazia com que as mulheres não se sentissem

1 A segunda onda feminista, que sucedeu às lutas pelo voto das mulheres, caracterizou-se, sobretudo, pela reivindicação do direito à educação e ao trabalho, das chamadas "sufragistas" do final do século XIX e início do XX. 
incluídas, pois suas diferenças de raça, classe, condições e oportunidades eram invisibilizadas. A consideração de múltiplas diferenças, reivindicadas inicialmente pelas mulheres negras, constituiu-se em uma produção importante dos estudos de gênero, a partir do conceito de interseccionalidade (CRENSHAW, 2002)².

Na América Latina, as interseccionalidades permeiam também os estudos decoloniais ${ }^{3}$ que pautam a consideração das situações coloniais das populações originais indígenas, vítimas das opressões e genocídio pelos colonizadores europeus, e dos povos africanos trazidos para o continente na condição de escravizados. Condições de violência, discriminação e vulnerabilidade, que se perpetuam tanto entre descendentes das nações indígenas remanescentes como de afrodescendentes, que compõem parte significativa da população de muitos de nossos países. Uma importante contribuição aos estudos decoloniais, relacionada às condições das mulheres indígenas e das mulheres negras no continente, foi dada pela teórica latinoamericana María Lugones (2019), entre outras.

A produtiva relação entre ativismo e teoria, ocorreu também com os estudos de sexualidades, ligados aos movimentos homossexuais, centrados inicialmente nas homossexualidades masculinas, nas mulheres lésbicas, e mais recentemente, abrangendo as transexualidades. Estudos dos chamados grupos identitários, reivindicando reconhecimento e direitos cidadãos ${ }^{4}$.

Revisitando o texto clássico, publicado em 1985, de Albertina Costa, Carmen Barroso e Cynthia Sarti, com um balanço das pesquisas sobre mulher no Brasil, que consta em coletânea teórica recentemente lançada (HOLLANDA, 2019), acompanhamos o processo de constituição do campo dos estudos feministas e de gênero no país. Campo que se estruturou a partir da imbricação entre militância e academia e, com a incorporação da categoria gênero, que atenta para a construção relacional de feminino e masculino, abriu-se para os estudos LGBTs $^{5}$ e para as pesquisas sobre masculinidades.

No texto mencionado, Costa, Barroso e Sarti (HOLLANDA, 2019) analisam a produção brasileira sobre mulher/es na relação com o movimento feminista entre os anos 70 e parte dos 8o, detendo-se também nos temas dessas pesquisas, que destacam as questões das desigualdades, da profissionalização, do trabalho e, entre outros, o problema da violência de gênero. Tema que se vai constituindo como

\footnotetext{
2 Na definição de Kimberlé Crenshaw (2002, p.177),“A interseccionalidade é uma conceituação do problema que busca capturar as consequências estruturais e dinâmicas da interação entre um ou mais eixos da subordinação (...) trata especificamente da forma pela qual o racismo, o patriarcalismo e a opressão de classe e outros sistemas discriminatórios criam desigualdades básicas que estruturam as posições relativas de mulheres, raças, etnias, classes e outras".

3 Para um aprofundamento deste conceito e sua especificidade frente aos estudos pós-coloniais e descoloniais, consultar Luciana Ballestrin (2013).

4 Foi este movimento de estudantes feministas negras que se expressou na intervenção artística e política desencadeadora dos conflitos discursivos contidos nas imagens analisadas neste artigo.

5 Entre as muitas siglas utilizadas neste campo, enfatizamos aqui a referência aos estudos de lésbicas, gays, bissexuais e trans, abrangendo travestis e transexuais. Para uma complexificação das terminologias, conferir Regina Fachini (2005).
} 
de grande relevância na produção da área dos estudos feministas, de gênero e de homossexualidades, os quais se expandem na atualidade, com as teorias queer.

Falar dessa questão hoje remete às lutas e conquistas jurídicas relacionadas à Constituição de 1988 e ao papel que os movimentos e organizações de mulheres desempenharam na Constituinte, para a visibilização das violências contra mulheres e sua consideração como questão de saúde e direitos humanos, com demandas urgentes de políticas públicas específicas. Conquistas que, passando por medidas ditadas por organizações internacionais em tratados assinados pelo Brasil, levaram à criação, através da Lei 9.099/95, dos Juizados Especiais Criminais (JECRIM's), para julgar os crimes de menor potencial ofensivo, enquadrando entre estes as agressões contra mulheres (BANDEIRA, 2019). Em função dos questionamentos a esse estatuto jurídico, a luta feminista levou à promulgação, em 2006, da Lei 11.340 - Lei Maria da Penha, voltada ao enfrentamento da violência contra a mulher. Sobre este percurso e a ampliação do entendimento e abrangência das violências de gênero, há uma grande produção acadêmica no país ${ }^{6}$, que culminou com a implantação em 2015, da Lei 13.104, que alterou o artigo 121 do Código Penal Brasileiro, passando a prever o feminicídio como crime de homicídio, inserido no rol de crimes hediondos.

Para os estudos de sexualidades, que sucedem os movimentos homossexuais e feministas, o tema da violência é central, pois diz respeito ao controle dos corpos, da reprodução, com a consequente normatização das práticas sexuais e a patologização das condutas dissidentes da imposição da heterossexualidade como norma. O campo dos estudos de sexualidades não normativas desenvolve-se em torno do combate às violências perpetradas contra as pessoas que não se aderem à heterossexualidade compulsória como prática e atitude identitária.

O movimento de mulheres negras, que iniciou com força em meio às lutas pela democratização do Brasil na ditadura militar, tem expressão significativa com a diversificação impactante dos feminismos militantes na academia hoje ${ }^{7}$. Movimentos de lutas contra a discriminação racial, que se perpetua no país e resulta em um verdadeiro genocídio de homens jovens negros e de pessoas negras em geral, foco de importante produção atual no âmbito dos estudos decoloniais ${ }^{8}$.

Os números de mortes por intolerâncias étnico/raciais, de feminicídios, de assassinatos de homossexuais, de pessoas trans, têm se mostrado alarmantes em diferentes sociedades. O pioneiro movimento do Grupo Gay da Bahia, buscando quantificar sistematicamente a morte de homossexuais no país (MOTT, 200o); o Instituto de Pesquisas Econômicas Aplicadas (IPEA, 2018), produzindo os Atlas

6 Conferir Heleietth Saffioti. Gênero, patriarcado, violência. São Paulo: Perseu Abramo, 2004; Saffioti, H. Violência de gênero: o lugar da práxis na construção da subjetividade. Lutas sociais, n.2, São Paulo, 2004, p.59-79; Cecília M. B. Sardenberg e Miriam P. Grossi (orgs) Dossiê Balanço sobre a Lei Maria da Penha. Revista Estudos Feministas. v.23, n.2, 2015. p. 497-617, entre outras produções.

7 Fato seguramente ligado às ações afirmativas que instituíram as políticas de cotas para o ensino superior, como também aos avanços tecnológicos, com a expressividade das comunicações em redes entre as gerações jovens, em especial.

8 Foi este movimento de feministas negras que se expressou na intervenção artística e política desencadeadora dos conflitos discursivos contidos nas imagens analisadas neste artigo. 
da Violência no Brasil, publicizando os homicídios de que são vítimas segmentos da população diferenciados por raça, gênero, classe social; internacionalmente, o Human Rigths Watch (2019/2018) que quantifica as violências relativas de diferentes países, e nos mostra que o Brasil tem protagonizado uma escalada da violência, ocupando lugar de destaque quanto ao assassinato de pessoas trans e de mulheres (os feminicídios que crescem exponencialmente em relação às mulheres negras), com impressionantes números de estupros, crime que, no entanto, é considerado subnotificado.

Os ataques, as violências de gênero que chegam aos desfechos dramáticos revelados por estes mapas/relatórios, acontecem em todos os ambientes e instituições, família, escola, igreja, trabalho, e geralmente são precedidos de outras formas mais sutis de violências, as psicológicas, morais, humilhações, ameaças, desqualificações (BRASIL, 2006; MACHADO, 2017). Os estudos de masculinidades, que sucederam a utilização da categoria gênero nesta área de produção acadêmica (militante), trabalharam inicialmente com o conceito de masculinidade hegemônica (CONNELL \& MESSERSCHMIDT, 2013), aquele padrão de masculinidade que se impõe quase como um tipo ideal (Weber, 1999) sobre outras formas de se constituírem os sujeitos homens em contextos sociais, com base nos modelos de socialização que aliam o masculino à violência, ao repúdio de manifestações emocionais, à sujeição das mulheres e de outras manifestações de feminilidade. $\mathrm{O}$ que atualmente o próprio senso comum designa como masculinidade "tóxica", caracteristicamente misógina e homofóbica.

Foi este tipo de manifestação que se evidenciou nas imagens, cartazes e notícias referidos neste artigo, opondo estudantes homens, com violentas ameaças e afirmações de masculinidade tóxica carregadas de expressões de misoginia e homofobia, a mulheres que se posicionavam como feministas e foram caracterizadas como lésbicas na intervenção agressiva do cartaz que as ameaçava de estupro. O que nos levou a este parêntese na análise dos discursos, em confronto neste episódio, que se prolongou e extrapolou o ambiente universitário na UFPR.

\section{Tensões discursivas e relações de gênero nas paredes da universidade}

O Departamento de Arquitetura e Urbanismo (DAU), da UFPR, pertence ao Setor de Tecnologia, e está localizado no campus Centro Politécnico (Figura 1), local que abriga também os setores de ciências exatas, ciências biológicas e ciências da terra da instituição. O Centro Politécnico está localizado em uma área ampla, arborizada, sendo constituído por diferentes prédios destinados ao funcionamento dos cursos, laboratórios e empresas juniores. 
Figura 1: Imagem aérea do Centro Politécnico da UFPR.

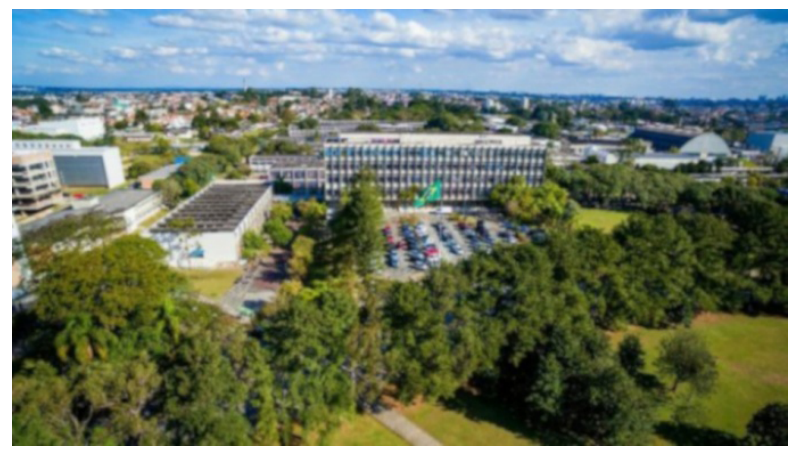

Fonte: Bem Paraná (2017)

A seguir, descreveremos o encadeamento de acontecimentos objetivados por intervenções gráficas nas paredes do DAU no ano de 2015, foco de análise.

Na UFPR, bem como em outras universidades federais, é comum entre estudantes de coletivos feministas a prática de colar cartazes, utilizando estêncil ou outros métodos gráficos para divulgar mensagens de combate ao machismo e à homofobia. Essa situação também ocorre no curso de Arquitetura e Urbanismo e um exemplo são as intervenções feitas em um espaço conhecido como estufa, lugar de convivência de estudantes (Figura 2).

Figura 2: Imagem de busto colocado em edificação do DAU.

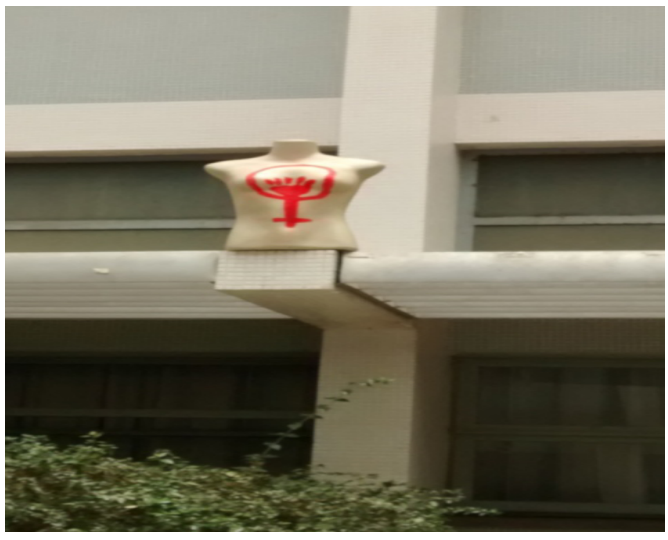

Fonte: arquivo das pesquisadoras

Em um pilar, que se apresenta à frente da edificação, no limite entre a edícula que separa a parte interna da parte externa, foi colocado o busto de um manequim, conforme se observa na imagem acima. Uma forma, à primeira vista, indefinível sob o ponto de vista de gênero, podendo ser considerada feminina devido ao volume que sugere seios. Sem cabeça, sem braços, esse manequim de cor neutra traz, em seu dorso, a imagem de um símbolo, pintado na cor vermelha. Trata-se de um 
punho cerrado inserido no símbolo de Vênus, o qual representa o feminismo negro9. Instalar o busto naquele local, à vista de todos/as, foi um modo de marcar presença, de visibilizar a luta de mulheres que historicamente sofrem violências de variadas ordens e são vítimas de feminicídios cujos números crescem assustadoramente no Brasil.

A resposta à presença desse busto não tardou. Conforme amplamente divulgado por meio de jornais, blogs e redes sociais (BATISTA, 2015; BORDIN, 2015; REDAÇÃO BONDE, 2015), em um fim de semana do mês de maio de 2015, foram afixados nas paredes do departamento cartazes contendo mensagens com conteúdo homofóbico e de apologia ao estupro, aparentemente em resposta às intervenções feministas feitas anteriormente.

Figura 3: Cartaz afixado a uma parede do DAU.

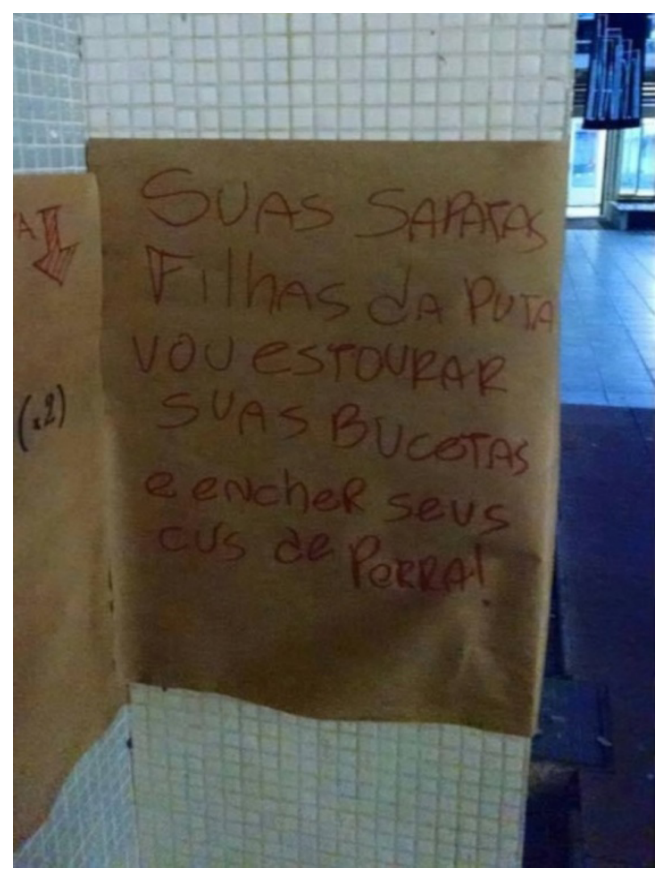

O teor dos cartazes afixados, como se vê na figura 3, escancarava a violência de gênero. "Suas sapatas/filhas da puta/vou estourar suas bucetas e encher seus cus de porra!”. Não deixavam dúvidas sobre a condição axiológica de seus autores, bem

\footnotetext{
9 "O gesto de erguer o punho foi usado pelo movimento Panteras Negras e ganhou fama nas Olimpíadas de 1968, no México, quando dois atletas negros, Tommie Smith e John Carlos, protestaram no pódio contra a discriminação racial com os punhos fechados erguidos, cobertos com luvas pretas. Naquele ano, Martin Luther King havia sido assassinado. O gesto se tornou um símbolo inconfundível do movimento Black Power. Inserido dentro do espelho de Vênus, o punho passou a representar também o movimento das mulheres negras" (https://azmina.com.br/reportagens/simbolos-do-feminismoquais-sao-e-o-que-significam/). Sobre o feminismo negro, sua epistemologia e lutas, conferir ainda Patricia Hills Collins (2019), Oyèrónké Oyewùmí (2019), entre outras.
} 
como suas visões de mundo no que se refere às relações de gênero e ao modo como as mulheres que se opõem às suas visões de mundo devem ser tratadas.

Figura 4: Cartazes feministas em respostas às ameaças machistas.

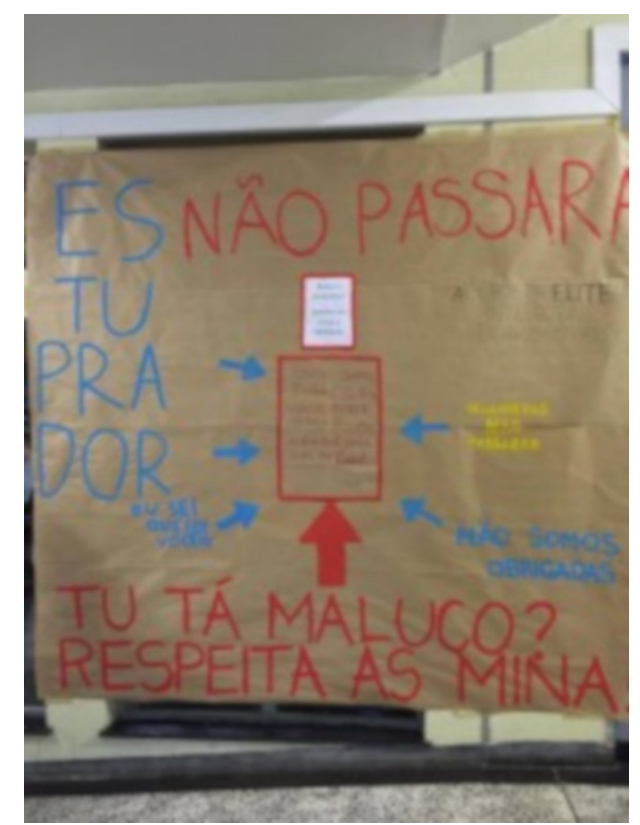

Fonte: GAU/UFPR

Os grupos feministas, por sua vez, recolheram esses cartazes e os reutilizaram em uma nova intervenção, em resposta às agressões. Além disso, cobriram as paredes do curso com mensagens feministas, fazendo uso novamente de cartazes e estêncil, tal como se pode observar na Figura 4, na qual localizamos, ao centro, o cartaz apresentado na Figura 3 e, em torno desse, intervenções com os dizeres: "Estuprador/ Tu ta maluco? Respeita as mina ${ }^{10} /$ Não somos obrigadas", entre outros dizeres.

De acordo com as referências supracitadas, a posição da chefia do departamento, diante desse conflito, foi de repreender verbalmente às feministas, alertando-as de que o ato se configurava como depredação do patrimônio público e de que elas estariam sujeitas a processos administrativos (BORDIN, 2015). Em seguida, a maior parte das mensagens foi apagada e os cartazes retirados.

Chama a atenção o fato de as alunas terem sido repreendidas como depredadoras do patrimônio público. Elas foram advertidas, o que não ocorreu com os alunos autores dos cartazes com mensagens violentas como a que se vê na figura 3. A resposta agressiva e criminosa, já que ameaçava de estupro as responsáveis pela colocação do

10 "Respeita as minas" é frase que aparece em outras manifestações do movimento feminista. Débora Visini (2015) analisa sua presença no campus da UFPB, destacando a importância da pichação nas lutas de mulheres. Para a autora, "As pichações já são dadas como ações políticas, pois rompem com a continuidade de uma ordem, por meio do dissenso. Quando o conteúdo dessas ações é o feminismo, elas se tornam ferramentas políticas duplamente, pois se estabelecem como estéticas de resistência” (p.320). 
busto em espaço público, não foi recriminada. Não houve investigação para apurar os responsáveis, e suas palavras, uma vez que não reprimidas, continuaram a ecoar naquele espaço.

$\mathrm{O}$ que pode ter motivado as autoridades institucionais a silenciarem em relação às agressões machistas? Por que interviram somente quando houve a resposta das próprias estudantes às agressões sofridas? Talvez, a resposta das autoridades tenha acontecido em virtude da dimensão que o conflito passou a tomar e por terem sido as estudantes feministas as iniciadoras das intervenções. Mas, a primeira intervenção, a colocação do busto, em si, não anunciava a intenção de iniciarem um conflito, ao contrário, marcava presença e afirmava que vidas de mulheres negras e suas lutas importam. A omissão em relação à violência das palavras inscritas no cartaz, retratado na figura 3, é que impressiona, pois, o fato da autoridade universitária não ter incluído os alunos homens na repreensão contendo ameaça de processo administrativo, de certa forma os isenta da responsabilidade pelas tensões e os conflitos deflagrados, bem como pela própria necessidade de as mulheres terem de afirmar em público suas lutas.

Analisemos a arena de vozes presente nessa cadeia de enunciados. Afirma Bakhtin (2003, p. 301): "A quem se destina o enunciado, como o falante (ou o que escreve) percebe e representa para si os seus destinatários, qual é a força e a influência deles no enunciado - disto dependem tanto a composição quanto, particularmente, o estilo do enunciado".

Nesse caso, percebemos que há uma tensão entre grupos de estudantes com opiniões fortemente opostas. É nas paredes e nos espaços de convivência pelos quais os estudantes circulam, que eles buscam formas de comunicar ideias, cujas composições correspondem à força de conteúdos carregados de afetividade. Aos enunciados feministas, endereçam-se enunciados machistas que fazem uso de ameaças do crime de estupro. A estes, novas intervenções anunciam a resistência feminista, questionando a sanidade dos autores das ameaças e destacando a perplexidade causada pelos enunciados: "Tu ta maluco?/ Não passará/ Não somos obrigadas". A tensão entre discursos, as diferentes subjetividades, os conflitos do cotidiano universitário, expressão de embates que se apresentam em esferas sociais outras, são desse modo escancarados por escrito nas paredes do departamento.

Uma das intervenções mostra-se especialmente intrigante por revelar a arena de vozes vivas e objetivadas em um dos corredores do departamento (Figura 5). 
Figura 5: Diálogo escrito em parede do DAU.

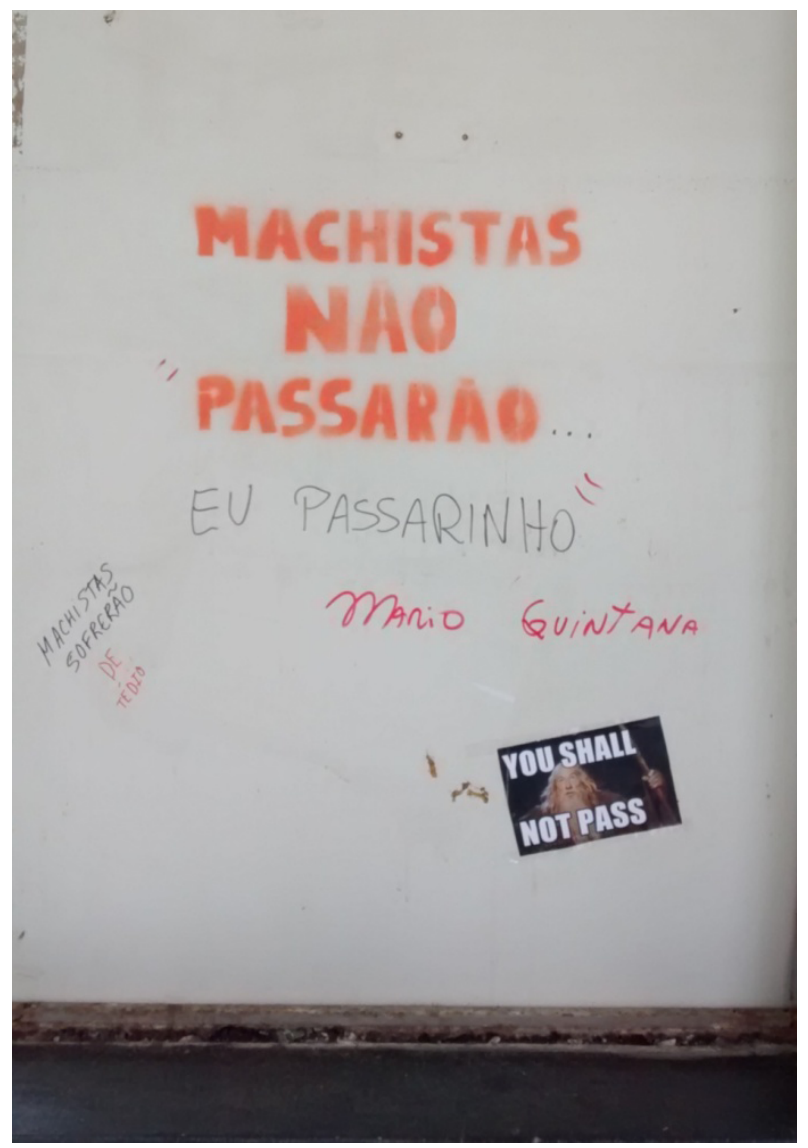

Fonte: arquivo das pesquisadoras.

Para analisarmos a imagem, vamos recorrer novamente a Bakhtin (2003) e às suas observações sobre a posição responsiva do sujeito na cadeia de enunciados:

(...) o ouvinte, ao perceber e compreender o significado (linguístico) do discurso, ocupa simultaneamente em relação a ele uma ativa posição responsiva: concorda ou discorda dele (total ou parcialmente), completa-o, aplica-o, prepara-se para usá-lo, etc. (...) Toda compreensão da fala viva, do enunciado vivo é de natureza ativamente responsiva (embora o grau desse ativismo seja bastante diverso); toda compreensão é prenhe de resposta, e nessa ou naquela forma a gera obrigatoriamente: o ouvinte se torna falante (...). Cada enunciado é um elo na corrente complexamente organizada de outros enunciados (BAKHTIN, 2003, p. 271-272).

Observando a imagem, podemos concluir que essa cadeia de enunciados é inaugurada com a frase "Machistas não passarão", gravada em estêncil e, que, por sua vez, responde a outros que o precederam. Logo abaixo, outra intervenção 
completa a frase com as palavras "eu passarinho", referência ao Poeminho do contra", de Mário Quintana que, da forma como se apresenta, e na relação com aquele que o antecede, o satiriza. Adiante, outra caligrafia registra a autoria do poeta, o que nos mostra que a sátira foi compreendida, a autoria afirmada, o sentido compartilhado, engendrando uma nova resposta na cadeia. Essa atua em direções paradoxais: por um lado, "poemiza" o enunciado primeiro, e ao fazê-lo, satiriza os termos do conflito, amenizando a potência política da afirmação primeira, contribuindo para que se dissolva.

Mais abaixo, ainda na mesma parede e dialogando com as intervenções anteriores, foi afixada uma figura com a imagem do personagem Gandalf, da trilogia O Senhor dos Anéis, de J. R.R. Tolkien, conforme caracterizado na sequência cinematográfica do diretor Peter Jackson. Sobreposta à imagem do personagem, há uma famosa frase por ele anunciada nesse filme: "You shall not pass", que em inglês significa "Você(s) não passará(ão)". Essa frase, portanto, remete ao contexto extraverbal do filme, fazendo referência à linguagem artística e possibilitando a criação de novos sentidos para a frase. O enunciado poderia ser assumido como mais uma maneira de satirizar a frase inicial, ou talvez de fazer referência ao personagem do filme: um bruxo, que, por sua vez, estaria associado às características de poder e resistência, acrescentando, nesse caso, força à voz das feministas.

No canto inferior esquerdo da imagem temos uma nova intervenção: "Machistas sofrerão", enunciado que entra em consonância com a mensagem inicial de cunho feminista. Mas, em seguida, encontramos nova intervenção que dá sequência a essa última frase com os dizeres "de tédio", construindo assim uma contrapalavra àquela voz, compartilhando o sentido de uma voz outra, a qual, opondo-se ao discurso feminista, classifica-o como chato e tedioso, desqualificando-o.

A cadeia de enunciados, que ali se estabeleceu, foi iniciada por uma primeira intervenção-enunciado (primeira no espaço daquela parede, já que, enquanto expressão discursiva, estava responsivamente posicionada na arena de vozes sociais constituídas entre as/os estudantes). Todavia, não somente nessa cadeia discursiva o enunciado foi posicionado. Os dizeres também foram anunciados em um espaço físico determinado, em uma parede grande, sem intervenções outras, no corredor do departamento e, assim, apresentaram sua conclusibilidade ${ }^{12}$ enunciativa (BAKHTIN, 2003), ao mesmo tempo em que ofereceram espaço para as respostas seguintes. Isto é, os espaços físico e discursivo se amalgamaram na construção dessa expressão concreta da arena de vozes que circulam pelo Departamento de Arquitetura e Urbanismo daquela universidade.

11 "Todos esses que aí estão/ Atravancando o meu caminho, / Eles passarão.../ Eu passarinho!" (QUINTANA, 2013).

12 De acordo com Bakhtin (2003), "a conclusibilidade do enunciado é uma espécie de aspecto interno da alternância dos sujeitos do discurso; essa alternância pode ocorrer precisamente porque o falante disse (ou escreveu) tudo o que quis dizer em dado momento ou sob dadas condições. (...) O primeiro e mais importante critério de conclusibilidade do enunciado é a possibilidade de responder a ele, em termos mais precisos e amplos, de ocupar em relação a ele uma posição responsiva" (p. 28o, grifos do autor). 
Para analisar o modo como a instituição se posiciona nessa arena, destacamos um cartaz afixado pela direção do DAU, com os dizeres: "Consideração/ com o patrimônio público/ com as pessoas ao redor, e as que vêm limpar/ com a atividade acadêmica/ Departamento de Arquitetura e Urbanismo”. (Figura 6).

Figura 6: Aviso na parede do DAU.

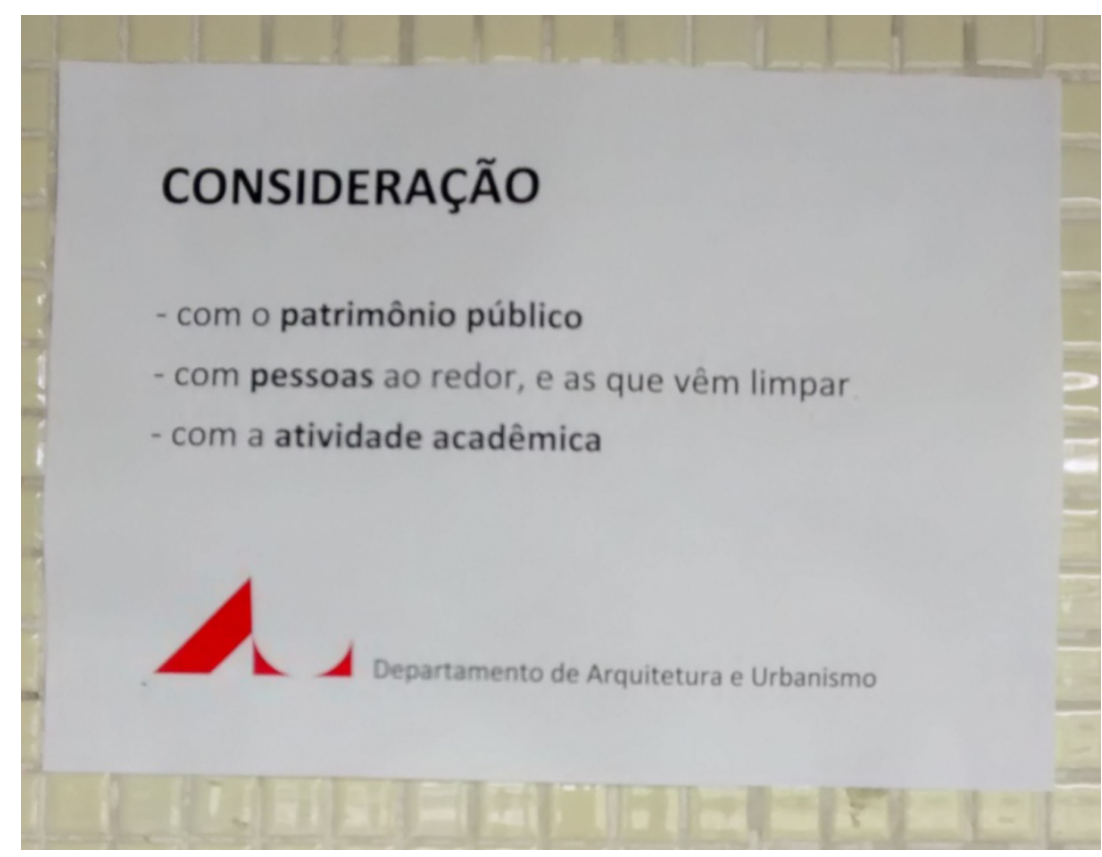

Fonte: arquivo das pesquisadoras.

Articulando a cadeia de eventos analisada aos dizeres do cartaz, avaliamos que a voz da instância institucional diretiva do DAU se fez soar mais alto do que a voz das militantes feministas, não pelo uso do verbo, mas pela ordem do silêncio. Tal feito se realizou por meio da repreensão verbal a que foram submetidas as estudantes, exortação essa que, fundamentada na exigida conservação do patrimônio público, culminou na determinação de apagamento das intervenções nas paredes. Paralelamente, por meio do aviso afixado, a instituição reforça a ordem inicial, mencionando as pessoas participantes do espaço universitário, e apresentando as atividades acadêmicas como meio para fortalecer seu discurso.

Vemos que o pedido do cartaz é bastante amplo. O que seria preciso fazer para se ter "consideração"? Quem seriam as "pessoas" a quem ela é solicitada e "ao redor" do que elas estariam? Ter consideração, nesse caso, parece significar um pedido para que as estudantes não denunciem nos espaços físicos do patrimônio público os conflitos vivenciados neles, pois isso fere a harmonia estética e moral da universidade. Ao fazer isso, a instituição se esforça por homogeneizar os espaços e silenciar as tensões. Em outros termos, ao proibir os escritos e lavar as paredes, tenta-se lavar também as discordâncias, os ruídos, as diferenças que tão fortemente marcam as relações acadêmicas, institucionais e cotidianas na universidade. Estranho 
é o fato de as autoridades institucionais não se preocuparem com as denúncias das estudantes em relação aos comportamentos que atualizam os conflitos e que ameaçam à integridade física das pessoas que transitam por esses ambientes. Estranho é não se perguntarem por que as estudantes precisam anunciar, na forma de cartazes ou bustos colocados em locais de ampla circulação, algo que, provavelmente, se não sofressem cotidianamente, não precisaria estar ali. Conflitos e tensões aparecem, responsivamente, nos enunciados dos estudantes e continuam a causar rupturas nas paredes do departamento, resistindo às ordens que silenciam as tensões.

Vale destacar que esse mesmo Departamento, que se ampara na necessidade de conservação do patrimônio para proibir intervenções fora de locais designados, não consegue fazer cumprir a manutenção estética do seu próprio espaço. De que modo isso se evidencia?

Na Figura 7, vemos a fotografia de um mural destinado à divulgação de editais no DAU. Neles, foram dispostos editais de seleção para projetos de extensão e monitoria realizados em 2008, ou seja, sete anos antes da ocorrência dos eventos aqui analisados. Junto a esses, são observados muitos papéis amassados que parecem ter sido jogados para dentro do vidro que protege o mural.

Figura 7: Mural do afixado em parede do DAU.

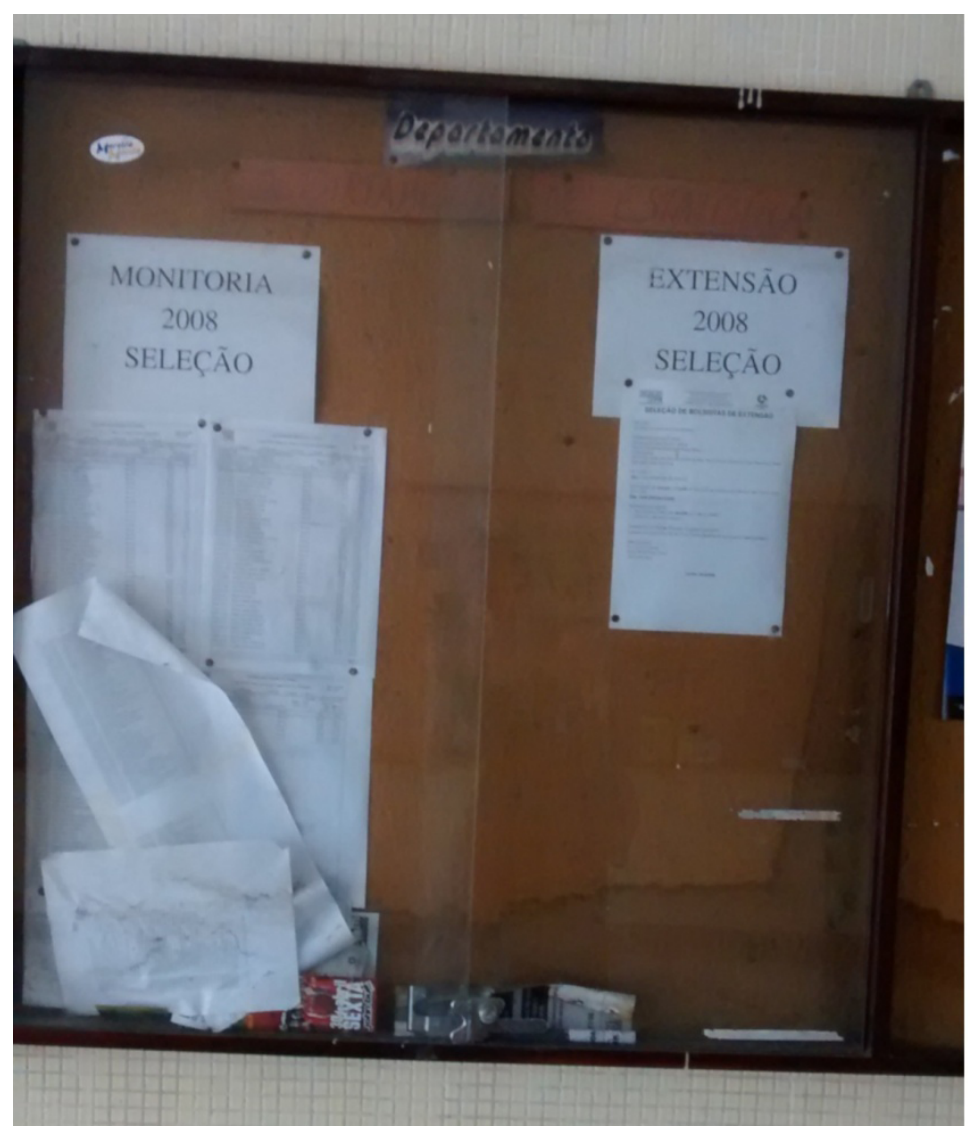

Fonte: arquivo das autoras. 
Certamente, do ponto de vista institucional, o peso da discussão sobre gênero e violência e suas consequências para a desestabilização da ordem universitária são muito maiores do que a necessidade de atualização da informação institucional divulgada e a conservação dos editais destinados a essa função.

É importante mencionar que em resposta aos acontecimentos aqui relatados e a outras situações semelhantes, que explicitam as violências de gênero tão frequentes na atualidade, a UFPR criou, no ano de 2015, a Plataforma Conte Conosco (UFPR, 2015). Envolvendo profissionais da assistência, professores e coletivos da universidade, a plataforma idealizava constituir um canal online que possibilitasse às/aos estudantes solicitar orientações ou fazer denúncias de casos de violência e discriminação ocorridos no âmbito da universidade. Previa ainda o encaminhamento das situações para profissionais das áreas do Direito, Psicologia e Serviço Social.

No ano de 2017, após a mudança da gestão da universidade, a UFPR criou a Superintendência de Inclusão, Políticas Afirmativas e Diversidade (SIPAD), unidade executiva central, vinculada ao Gabinete da Reitoria, que definiu como missão "propor, fortalecer e concretizar políticas de promoção de igualdade e de defesa dos direitos humanos junto às práticas inclusivas empenhadas pela Universidade Federal do Paraná" (UFPR, 2019). Conforme apresentado no site institucional da UFPR, a SIPAD foi proposta para assumir funções de desenvolvimento e fortalecimento de ações afirmativas direcionadas a diferentes grupos sociais que compõem o contexto universitário, incluindo-se aqui:

(...) pessoas com necessidades especiais, com deficiência, altas habilidades/superdotação, surdos/as, negros/as, indígenas, quilombolas, comunidades tradicionais, povos do campo, mulheres, LGBTIs, migrantes, refugiados/as, solicitantes de refúgio ou portadores/as de acolhida humanitária, apátridas e outros grupos histórica e socialmente subalternizados, no âmbito acadêmico, pedagógico e institucional da comunidade da UFPR. (UFPR, 2019).

No que tange às situações que envolvem preconceito e violência aos grupos contemplados, incluindo aqui questões degênero, a SIPAD possui atualmente um canal direto para denúncias e acolhimento de ocorrências. Essas situações são recebidas por profissionais da psicologia e do serviço social que, por sua vez, desenvolvem ações de assistência junto às diferentes instâncias universitárias responsivamente às demandas recebidas.

Reconhecemos que os movimentos de criação de espaços para o acolhimento de situações de violência são iniciativas importantes de assistência às/aos estudantes e promoção de condições de permanência e qualidade de vida das/os estudantes. Porém, é preciso fortalecer as ações que superem a assistência às ocorrências específicas que acabam por individualizar as situações de violência na universidade, ou a negar que estas se voltam contra grupos específicos como, por exemplo, mulheres, 
tal como evidenciado neste artigo, ou travestis e transexuais, conforme analisado por Cunha e Silva (2016). É necessário que as ações institucionais propiciem visibilidade aos conflitos cotidianos, às violências de gênero, raça e outros demarcadores sociais, considerando sua interseccionalidade, criando condições para a construção de relações outras. Isso exige, dos diferentes atores da comunidade universitária, uma abertura para a discussão e posicionamento frente à realidade de violência que é cada vez mais comum nas universidades brasileiras.

\section{Considerações finais}

Violências de gênero são constantes nos noticiários brasileiros. De norte a sul do país, o aumento do número de estupros e feminicídios denuncia tensões históricas que clamam por ações efetivas, em variadas esferas, para que esses números possam deixar de existir. Trata-se de um esforço que precisa ser coletivo e que abranja tanto políticas públicas como ações cotidianas. Nas imagens analisadas neste artigo, é possível visibilizar como essas tensões estão presentes também nas universidades, atualizando profundas disputas e disparidades constituintes das relações de gênero e expressões de sexualidades entre os sujeitos em situação, que extrapolaram o campus universitário, chegando a veículos de comunicação de massa da cidade. $\mathrm{O}$ modo como os conflitos foram trabalhados pelas autoridades institucionais, por sua vez, denunciam a vigência de práticas de silenciamento e de individualização das situações de violência.

A pesquisa realizada possibilita compreender o modo como o espaço físico se converte, com as intervenções das/dos estudantes e autoridades institucionais, em um espaço dialógico de expressão dos acordos, disputas, (des)afetos que compõem a arena de vozes sociais da universidade pública. Ademais, o espaço é, por si só, constituidor de subjetividades, estabelecendo-se como um relevante lócus para as investigações que se dedicam às complexas relações entre o sujeito e a sociedade, e entre os sujeitos constituídos em diferenças interseccionadas de gênero, classe, raça, etnia e outras.

\section{Referências}

BAKHTIN, Mikhail. Estética da criação verbal. São Paulo: Martins Fontes, 2003.

BAKHTIN, Mikhail. Para uma filosofia do ato responsável. São Carlos: Pedro \& João Editores, 2012.

BALLESTRIN, Luciana. A América Latina e o giro decolonial. Revista Brasileira de Ciência Política. n.11, 2013, p. 89-117. 
BANDA B. Cartazes machistas expostos dentro do Centro Politécnico da UFPR revoltam acadêmicos. Foto: Cartaz afixado a uma parede do DAU. Divulgação Centro Acadêmico de Filosofia. 27 de maio de 2015.

BANDEIRA, Lourdes Maria. Violência de gênero; a construção de um campo teórico e de investigação. In: HOLLANDA, Heloisa Buarque de (org). Pensamento feminista brasileiro: formação e contexto. Rio de janeiro: Bazar do Tempo, 2019.

BATISTA, Rodrigo. Estudantes pedem que UFPR investigue ameaças de estupro. Gazeta do povo. Vida e cidadania. 27 de maio de 2015.

BEM PARANÁ. UFPR terá a maior usina solar fotovoltaica do Paraná. 30 de setembro de 2017. Disponível em: http://www.bemparana.com.br/noticia/529250/ufpr-tera-amaior-usina-solar-fotovoltaica-do-parana. Acesso em: 16 mar. 2020.

BORDIN, Laura Beal. Sociedade omissa, universidade omissa. Curitiba Cult, 30 de maio de 2015. Disponível em: http://curitibacult.com.br/sociedade-omissa-universidadeomissa/. Acesso em: 28 nov. 2015.

BRASIL. Lei 11.340, de 07 de agosto de 2006 (Lei Maria da Penha). Disponível em http://www.planalto.gov.br/ccivil_03/_ato2004-2006/2006/lei/l11340.htm. Acesso em: 29 jan. 2019.

COLLINS, Patrícia Hill. Pensamento Feminista negro: conhecimento, consciência e a política do empoderamento. São Paulo: Boitempo, 2019.

CONNELL, Robert; MESSERSCHMIDT, James. Masculinidade hegemônica: repensando o conceito. Revista Estudos Feministas, vol.21, n.1. 2013, p.241-282.

COSTA, Albertina de Oliveira; BARROSO, Carmen \& SARTI, Cynthia. Pesquisa sobre mulher no Brasil: do limbo ao gueto? In: HOLLANDA, Heloisa Buarque de (org). Pensamento feminista brasileiro: formação e contexto. Rio de janeiro: Bazar do Tempo, 2019, p. 109-134.

CRENSHAW, Kimberlé. Documento para o encontro de especialistas em aspectos da discriminação racial relativos ao gênero. Revista Estudos Feministas, vol.10, n.1. 2002, p.171-188.

CUNHA, Camila \& FÉLIX-SILVA, Antonio. O que te alucina? Banheiros, pichações e processos de subjetivação em gênero. Revista Periódicus. vol. 1, n. 6. 2016, p. 166-178. 
FACHINI, Regina. Sopa de letrinhas?: movimento homossexual e produção de identidades coletivas nos anos 9o. Rio de Janeiro: Garamond, 2005.

GAU/UFPR. Foto: Cartazes feministas em respostas às ameaças machistas. Publicado em BORDIN, Laura Beal. Sociedade Omissa, Universidade Omissa. Curitiba Cult, 30 de maio de 2015 .

HOLLANDA, Heloisa Buarque de. Pensamento feminista brasileiro: formação e contexto. Rio de janeiro: Bazar do Tempo, 2019.

HUMAN RIGHTS WATCH/Observatório dos Direitos Humanos 2019, events of 2018. Printed in the United States of America ISBN-13: 978-1-60980-884-6

IPEA Instituto de Pesquisa Econômica Aplicada; (FBSP) Fórum Brasileiro de Segurança Pública. Atlas da Violência 2018 http://www.ipea.gov.br/atlasviolencia/ filtros-series/3/violencia-por-raca-e-genero. Acesso em: 16 mar. 2020.

LUGONES, María. Rumo a um feminismo decolonial. In: HOLLANDA, Heloisa Buarque de (org). Pensamento feminista brasileiro: formação e contexto. Rio de Janeiro: Bazar do Tempo, 2019, p. 357-377.

MACHADO, Isadora Vier. Da dor no corpo à dor na alma: uma leitura do conceito de violência psicológica da lei Maria de Penha. Belo Horizonte: Editora D’Placido, 2017.

MOTT, Luiz. Manual de Coleta de informações, sistematização e mobilização política contra crimes homofóbicos. Salvador, Editora Grupo Gay da Bahia, 2000.

OYĚWÙMÍ, Oyèronké. La invención de las mulheres: uma perspectiva africana sobre los discursos occidentales del género. Bogotá: Editorial de la Frontera, 2017.

PIVA, Naiady. UFPR lança plataforma para receber denúncias de violência. Gazeta do povo. Vida e Cidadania. 12 de agosto de 2015.

QUINTANA, Mario. Caderno H. Rio de Janeiro: Objetiva, 2013.

REDAÇÃO BONDE. Estudantes protestam contra cartazes machistas expostos na UFPR. 27 de maio de 2015. Disponível em: http://www.bonde.com.br/?id_ bonde=1-12--204-20150527. Acesso em: 28 nov. 2015.

SAFFIOTI, Heleietth. Gênero, patriarcado, violência. São Paulo: Perseu Abramo, 2004.

SAFFIOTI, H. Violência de gênero: o lugar da práxis na construção da subjetividade. Lutas sociais, n.2. 2004, p.59-79. 
SARDENBERG, Cecília M. B.\& GROSSI, Miriam P. Dossiê Balanço sobre a Lei Maria da Penha. Revista Estudos Feministas, vol.23, n.2. 2015, p. 497-617.

SCOTT, Joan. Gênero, uma categoria útil de análise histórica. Revista Educação e Realidade, vol.16, n. 2. 1990.

TITTONI, Jaqueline \& ZANELLA, Andrea Vieira. Psicologia e fotografia: alguns desafios. Rio de Janeiro: Multifoco, 2016.

VISINI, Débora Machado. Gênero, Feminismo e Arte Urbana. In: Arte e política: IV Diálogos Internacionais em Artes Visuais e I Encontro Regional da ANPAP/NE. Recife: Editora UFPE, 2015, p. 311-334.

UFPR. Histórico. Universidade Federal do Paraná, 2017. Disponível em: http://www. ufpr.br/portalufpr/. Acesso em: 11 set. 2017.

UFPR. SIPAD - Superintendência de Inclusão, Políticas Afirmativas e Diversidade. Universidade Federal do Paraná, 2019. Disponível em: http://www.sipad.ufpr.br/ portal/. Acesso em: o8 ago. 2019.

WEBER, Max. A objetividade do conhecimento nas ciências sociais. In: COHN, Gabriel (org.). FERNANDES, Florestan (Coord.). Weber -Sociologia. Coleção Grandes Cientistas Sociais, 13. São Paulo: Ática, 1999, p. 79-127.

ZONTA, Graziele Aline \& ZANELLA, Andrea Vieira. Escritos nas paredes: tensões no contexto universitário. Rev. Polis e Psique. vol 9, n. 1. 2013, p. 167-185.

Recebido em 26/03/2020.

Aceito em 04/11/2020. 